\title{
El pintor monogramista: controversia historiográfica en torno al Retrato de Cristóbal Suárez de Ribera de Velázquez
}

\author{
El pintor monogramista: the historiographical controversy around \\ the Portrait of Cristóbal Suárez de Ribera by Velázquez
}

Carmen DE TENA RAMÍREZ

Universidad de Sevilla

ORCID: https://orcid.org/0000-0001-5460-0851 / cdetena@us.es

DOI: http://dx.doi.org/10.18002/da.v0i18.5482

Recibido: 6-VII-2018

Aceptado: 5-VII-2019

RESUMEN: Con el fin de contribuir al conocimiento del desarrollo disciplinar de la Historia del Arte en España, proponemos un análisis sobre el descubrimiento de una obra del pintor Diego Velázquez, el Retrato de Cristóbal Suárez de Ribera. Este suceso, acaecido a comienzos del siglo XX, nos permite comprender la evolución de los estudios histórico-artísticos en nuestro país y el papel fundamental que en él tuvieron los historiadores del arte procedentes de Alemania.

Palabras clave: Historiografía artística; August L. Mayer; Carl Justi; Valerian von Loga; José Gestoso.

ABSTRACT: The aim of this article is to contribute to the knowledge of the disciplinary development of Art History in Spain. To this end we present an analysis of the circumstances surrounding the discovery of Portrait of Cristóbal Suárez de Ribera by Diego Velázquez. This event, wich took place at the beginning of the 20th century, allows us to understand the evolution of historical-artistic studies in Spain and the essential role played by art historians from Germany.

Keywords: Art Historiography, August L. Mayer, Carl Justi, Valerian von Loga. José Gestoso.

La vida del pintor Diego Velázquez y su obra pictórica han inspirado y seguirán inspirando cuantiosos y variados trabajos de investigación. En el estudio que presentamos nos hemos querido centrar en la historiografía crítica entretejida en torno a este artista, concretamente en los primeros estudios metódicos realizados sobre su obra ${ }^{1}$. En

\footnotetext{
${ }^{1}$ El presente artículo se ha elaborado en el marco del proyecto "La Historia del Arte en España: desarrollo histórico y nuevas perspectivas" (CONCLABUS 2019/004), integrado en el convenio de investigación suscrito entre la Fundación de Cultura Andaluza y la
}

esta tarea, especialmente la de catalogación de sus pinturas, fue fundamental la aportación de historiadores del arte alemanes como Carl Justi, August L. Mayer y Valerian von Loga. Es por ello que queremos contribuir a esclarecer y valorar el papel desempeñado por los investigadores extranjeros en el desarrollo de los estudios histórico-artísticos en España. Para llevar a cabo este objetivo nos valdremos de un suceso que lejos de ser

Universidad de Sevilla. La autora es miembro del grupo HUM-213 "Centro de Investigación del Patrimonio Artístico Andaluz". 
meramente anecdótico, nos enseña a conocer y a comprender cómo fue el proceso de institucionalización de la Historia del Arte en nuestro país.

El acontecimiento que servirá de hilo conductor a lo largo de estas páginas es el descubrimiento y atribución del Retrato de Cristóbal Suárez de Ribera (Fig. 1) a Diego Velázquez. Efectivamente, se trata ésta de una obra de juventud del citado artista, firmada y fechada en $1620^{2}$. El retratado fue un destacado benefactor de la hermandad de San Hermenegildo de Sevilla, propietaria de la pintura $^{3}$. Hasta comienzos del siglo XX había estado atribuida a Francisco de Zurbarán, pero a partir de 1913 se comenzó a aceptar la adscripción a la mano de Velázquez que de ella hizo el historiador del arte alemán Valerian von Loga. No obstante, hasta que este especialista se pronunciara al respecto, fueron otros los encargados de discutir acerca de la paternidad de la pintura al poco tiempo de ser descubierta.

\footnotetext{
${ }^{2}$ Esta obra ha sido bien estudiada por la historiografía artística, razón por la que nos limitamos a consignar las referencias bibliográficas más significativas, excluyendo las fichas catalográficas: Valerian Von Loga, "Zur zeit bestimmung einiger werke des Velázquez", Jahrbuch der Königlich Preussischen Kunstsammlungen, vol. 34 (1913), 281-291; Juan de Mata Carriazo, “Correspondencia de don Antonio Ponz con el conde del Águila", Archivo Español de Arte y Arqueología, no 14 (1929), 157-183; Joan M. Ainaud de Lasarte, "Pinturas de procedencia sevillana", Archivo Español de Arte, no 73 (1946), 54-63; Bernardino de Pantorba, La vida y la obra de Velázquez (Madrid: Compañía Bibliográfica Española, 1955), no 17; Bernardino de Pantorba, Varia Velazqueña (Madrid: Ministerio de Educación Nacional, 1960); Julián Gállego, Velázquez en Sevilla (Sevilla: Arte Hispalense Diputación Provincial de Sevilla, 1974), 92 y 156; Jonathan Brown, Velázquez, painter and courtier (Yale: Yale University Press, 1986), 28-31; José López Rey, Velázquez (Colonia: Taschen, 1996), nº 19; Bonaventura Bassegoda, "Pacheco y Velázquez", en Velázquez y Sevilla. Estudios (Sevilla: Junta de Andalucía, 1999), 131; Antonia Morel D`Arleux, "Un posible dibujo preparatorio del retrato de D. Cristóbal Suárez de Ribera de Velázquez", Goya, no 298 (2004), 32-36.

${ }^{3}$ Actualmente se conserva en el Museo de Bellas Artes de Sevilla.
}

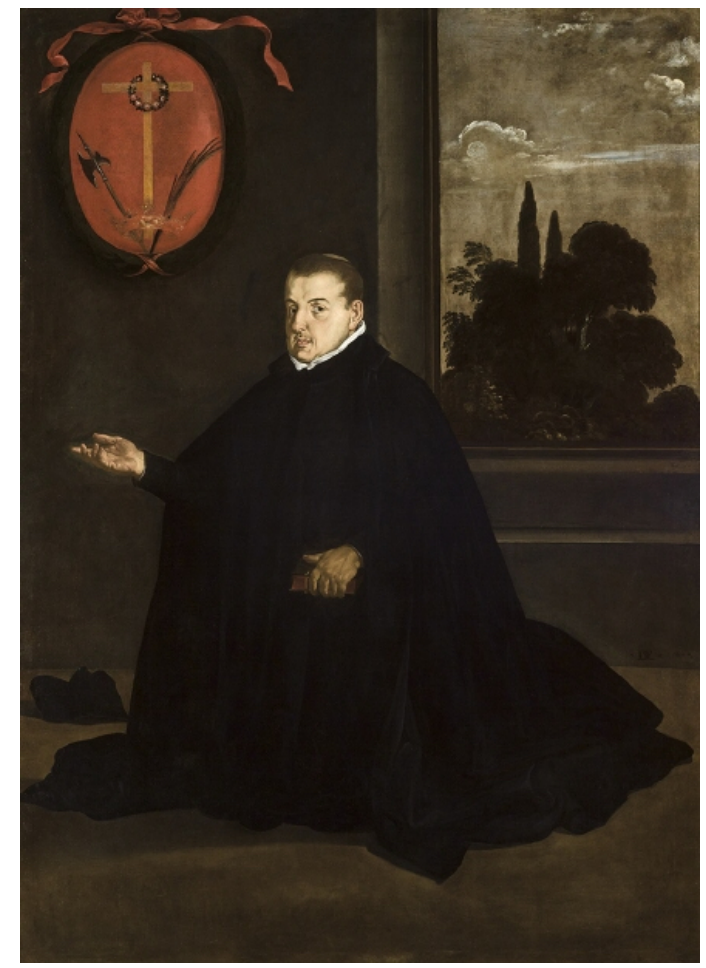

- Fig.1. Diego Velázquez. Retrato de Cristóbal Suárez de Ribera. 1620. Museo de Bellas Artes de Sevilla. Museo de Bellas Artes de Sevilla (propietario de los derechos)

Corría el año 1910 cuando el erudito José Gestoso ${ }^{4}$ se hallaba enfrascado en la organización de una exposición de retratos antiguos. Esta actividad formaba parte de la Exposición Obrera de Sevilla de aquel año, auspiciada por el político Cayetano Luca de Tena y Ossorio. Gestoso fue designado por éste para comisariar la muestra de retratos y por tanto fue suya la responsabilidad de buscar y seleccionar las obras que en ella iban a estar presentes. Durante la rebusca encontró interesante y muy acorde con la temática de la misma un retrato que estaba en la entonces capilla, hoy iglesia, de San Hermene-

${ }^{4}$ José Gestoso (Sevilla, 1852-1917) fue profesor de Teoría e Historia de las Bellas Artes de la Escuela de Artes e Industrias y Bellas Artes de Sevilla, profesión que simultaneó con otras actividades como el estudio de la historia y el arte sevillanos, la salvaguarda del patrimonio monumental, el diseño y la revalorización de la cerámica o la archivística, entre otras; una amplia visión del personaje en: Nuria Casquete de Prado Sagrera, José Gestoso y Sevilla: biografía de una pasión (Sevilla: Ayuntamiento de Sevilla, 2016). 


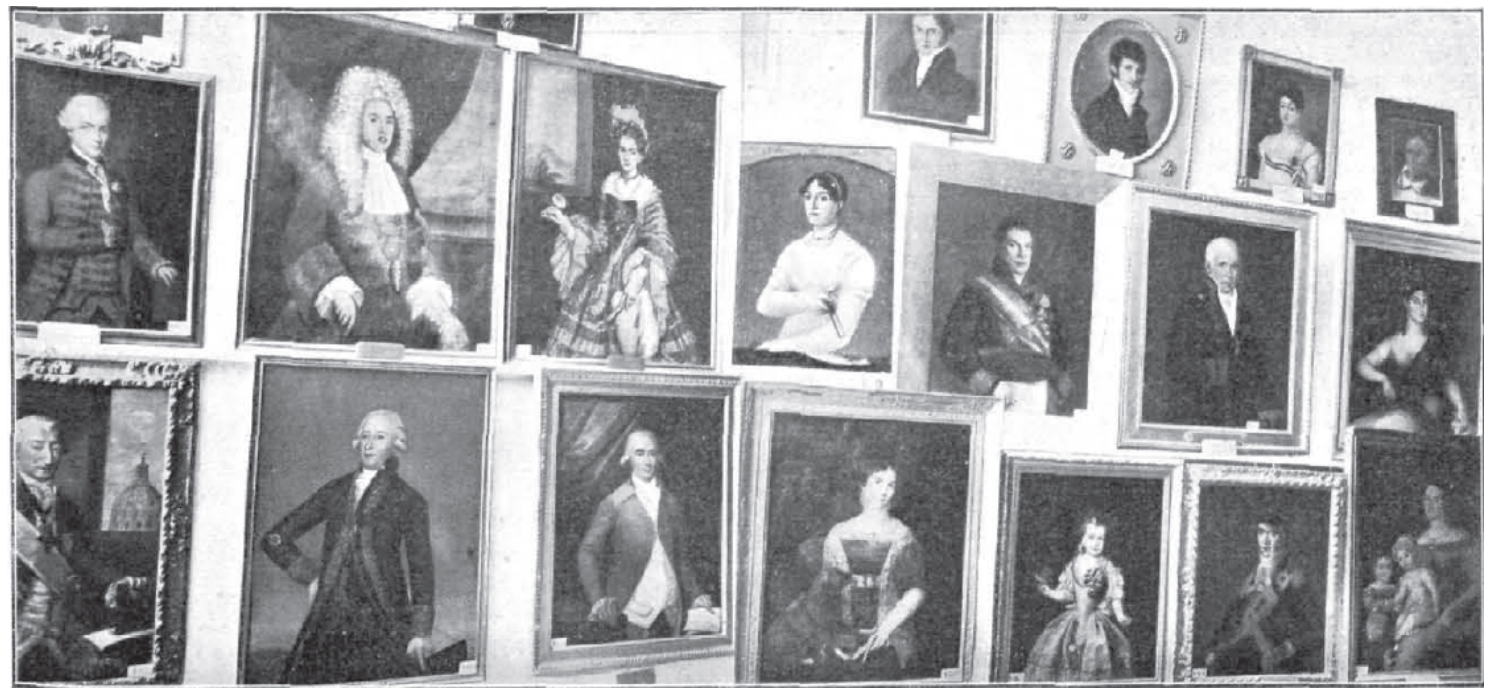

- Fig.2. J. Barrera (fotógrafo). Exposición de Retratos Antiguos de Sevilla. 1910. La Ilustración Artística (Barcelona) 16/05/1910, p. 115 (libre difusión)

gildo de Sevilla. Años atrás, Gestoso había recogido la existencia de esta pintura en su magna obra Sevilla Monumental y Artística, reconociéndola como el Retrato de Cristóbal Suárez de Ribera, benefactor de la hermandad de San Hermenegildo 5 .

Con el debido permiso de esta congregación, propietaria de la obra, Gestoso la llevó a la citada exposición de retratos, que fue instalada en los salones del Alcázar de Sevilla (Fig. 2), e inaugurada durante el mes de abril de $1910^{6}$. Antes de ser llevada a la

\footnotetext{
${ }^{5}$ Se desconoce la fecha de fundación de la hermandad de San Hermenegildo, pero existen noticias documentales que acreditan su existencia desde el siglo XV. Esta corporación se encargaba y encarga, pues pervive en la actualidad, del culto a san Hermenegildo en el templo que ocupa el lugar donde, según la tradición, fue encarcelado. La devoción suscitada por el santo, motivó que en 1606 se promoviera la construcción de una iglesia en el lugar donde se hallaba la capilla primigenia. El administrador de la hermandad, Cristóbal Suárez de Ribera, fue el principal impulsor de este proyecto, que finalizó con éxito a principios de 1616. En atención al importante trabajo desarrollado por Suárez de Ribera en la consecución de esta tarea, a su muerte fue sepultado en la nueva capilla, presidiendo su tumba el retrato que estamos estudiando, cfr. José Gestoso y Pérez, Sevilla Monumental y Artística, vol. III, (Sevilla: Oficina tipográfica de El Conservador, 1892), 286-291.
}

${ }^{6}$ Por fortuna, se publicó un catálogo de esta exposición de retratos, cuya edición, al igual que el patrocinio muestra pasó por un proceso de limpieza conducente a mejorar su contemplación ${ }^{7}$. Una vez quedó este retrato despojado de la suciedad que el paso del tiempo había depositado sobre su superficie, José Gestoso pudo apreciar con mayor detenimiento sus cualidades pictóricas, pero sobre todo, la existencia de una curiosa firma acompañada de una fecha entre los pliegues del traje del efigiado: “DovZ 1620" (Fig. 3).

Este descubrimiento animó a Gestoso a solicitar información acerca del retrato de Suárez de Ribera a sus propietarios. Tras la consulta previa del archivo, la hermandad le contestó: "Debo decirle, que en el inventario hay puestos varios cuadros y entre otros dice de ese: en el presbiterio, un cuadro al óleo de

de la misma, fue costeada por Cayetano Luca de Tena: José Gestoso y Pérez, Catálogo de la Exposición de retratos antiguos celebrada en Sevilla en abril de MCMX (Madrid: Oficina tipográfica de Blanco y Negro, 1910). Gestoso incluyó el retrato de Cristóbal Suárez de Ribera en el catálogo con un título erróneo, el de "V. P. Bernardino Suárez", tanto en el texto como en el correspondiente pie de fotografía que acompaña a la reproducción de la obra.

7 “El mucho polvo que obscurecía este lienzo cuando llegó á nuestras manos y su sobresaliente mérito, nos determinó a limpiarlo, como lo efectuamos, en unión del distinguido artista don José Lafita", Gestoso y Pérez, Catálogo de la Exposición..., s/p, no 12. 


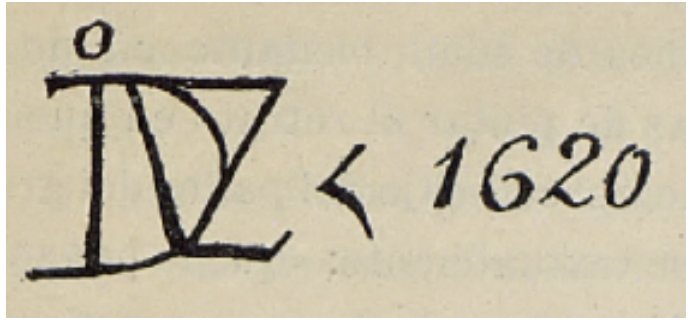

- Fig.3. J. Gestoso y Pérez. Monograma presente en el Retrato de Cristóbal Suárez de Ribera. "Un monograma y varias interpretaciones", Boletín de la Sociedad Española de Excursiones, vol. 18, 3, 1910, p. 131 (libre difusión).

Zurbarán, retrato del fundador D. Cristóbal Suárez de Ribera ${ }^{8 \prime}$.

A Gestoso no debió satisfacerle la información proporcionada por el inventario pues, si bien es una realidad que en su labor investigadora, a este erudito pocas veces le acompañaron las dotes necesarias para identificar a los artífices de las pinturas, contaba con que el estilo del retrato de Suárez de Ribera no congeniaba con las características de Zurbarán. Lo cierto es que José Gestoso fue un destacado estudioso del arte y la historia de Sevilla pero sus trabajos se fundamentaron más que en la contemplación y análisis de la obra de arte, en la documentación de archivo que fue recogiendo a lo largo de su vida. Su formación en la Escuela Superior de Diplomática de Madrid le confirió un talante marcadamente positivista y salvo excepciones, se mantuvo prácticamente durante toda su vida ajeno a las novedades metodológicas formalistas que se habían ido desarrollando en Alemania desde finales del siglo XIX'. Sa-

${ }^{8}$ Biblioteca Capitular y Colombina, Fondo Gestoso (BCC, FG). Correspondencia, 1910, vol. 1, nº 100, carta de Miguel García Miranda, con membrete de la "Ilustre Hermandad de caballeros de San Hermenegildo en Sevilla", a José Gestoso, fechada en Sevilla el 18/04/1910.

${ }^{9}$ Estas excepciones son sus estudios sobre cerámica, véase Alfonso Pleguezuelo Hernández, "Presentación", en José Gestoso y Pérez, Historia de los barros vidriados sevillanos: desde sus orígenes hasta nuestros días (Sevilla: Ayuntamiento de Sevilla, 1995), VII-XXIII. Sólo aplicó el método formalista en el estudio de la pintura al final de su vida, cfr. José Gestoso y Pérez, Biografía del pintor sevillano Juan de Valdés Leal (Sevilla: Juan P. Gironés, 1916). bedor de sus limitaciones, consultó con su colega y buen amigo August L. Mayer sobre el posible artífice del Retrato de Cristóbal Suárez de Ribera.

August L. Mayer fue el primer historiador del arte alemán en enfocar desde una metodología moderna el estudio del arte español ${ }^{10}$. Se declaraba con orgullo discípulo de Heinrich Wölfflin y por tanto en cuanto a su método de trabajo, se podría decir sin género de dudas que era un formalista convencido. Su objetivo fue el de aclarar mediante el análisis formal de las obras de arte los rasgos propios e identificativos de cada pintor, sin dejar de reconocer su individualidad artística. Por otro lado cabe señalar que sin abandonar el formalismo, Mayer estuvo interesado en imbricar el estudio de los artistas dentro de su contexto histórico, circunstancia que lo diferenció de otros colegas de profesión. Si tenemos en cuenta que los estudios histórico-artísticos desarrollados en España sobre la pintura española eran entonces escasos e imprecisos, es necesario reconocer la valiosa labor de Mayer en este campo $^{11}$. Como ha señalado Teresa Posada, contribuyó de forma decisiva al conocimiento y reconocimiento de la pintura española, especialmente gracias a sus aportaciones al campo catalográfico ${ }^{12}$.

\footnotetext{
${ }^{10}$ Para conocer a este personaje y comprender sus relevantes aportaciones a la Historia del Arte español, véase el excelente trabajo de: Teresa Posada Kubissa, August L. Mayer y la pintura española: Ribera, Goya, El Greco y Velázquez (Madrid: Centro de Estudios Europa Hispánica, 2010).

${ }^{11}$ No obstante y como ya ha indicado Javier Portús, entre 1885 y 1905 aparecieron obras fundamentales de la historiografía velazqueña, entre las que se encuentran las de dos españoles: Gregorio Cruzada Villaamil, Anales de la vida y de las obras de Diego de Silva y Velázquez (Madrid: Miguel Guijarro, 1885) y Aureliano de Beruete, Velázquez (Paris: Henri Laurens, 1898), cfr. Javier Portús, "Justi y Beruete, con Velázquez de por medio", en Carl Justi y el arte español, dir. por Antonio Bonet Correa, Henrik Karge y Jorge Maier Allende (Madrid: Centro de Estudios Europa Hispánica, 2015), 139-153.

${ }_{12}$ Posada Kubissa, August L. Mayer y la pintura..., 335-336.
} 
Con anterioridad a Mayer ya habían estudiado la pintura española otros especialistas alemanes pero fue especialmente destacada la aportación de Carl Justi (18321912), catedrático de Historia del Arte de la Universidad de Bonn ${ }^{13}$. A él se le debe una de las obras fundamentales existentes acerca del pintor Diego Velázquez, Diego Velázquez und sein Jahrhundert (Bonn, 1882) ${ }^{14}$. No en vano ha sido recientemente reconocido por el profesor Antonio Bonet Correa como un pionero en las investigaciones sobre el arte español de la Edad Moderna, además de fundador de la escuela de historiadores del arte español en Alemania ${ }^{15}$. Mayer también se sentía en cierta forma discípulo de Justi, a pesar de que este rechazaba de pleno el uso del método de trabajo formalista para el estudio del arte. Carl Justi era un firme defensor de la existencia del genio creativo y por esta razón, para él la historia del arte no atendía a criterios evolutivos. De esta forma, su única vía de estudio era a través de las biografías de los artistas. Aunque a simple vista este pudiera parecer un planteamiento más deudor del paradigma vasariano, lo cierto es que Justi introdujo en sus trabajos un factor determinante, esto es, el enfoque histórico cultural que motiva el estudio del arte dentro del contexto al que pertenece.

De vuelta a la controversia suscitada en

${ }^{13}$ Un acercamiento biográfico sobre el personaje en Karin Hellwig, "Carl Justi y los comienzos de la investigación sobre el arte español en Alemania", en Historiografía del arte español en los siglos XIX y XX (Madrid: C.S.I.C., 1995), 309-322. Recientemente se ha publicado un conjunto de estudios sobre Carl Justi: Carl Justi...

${ }^{14}$ La primera edición española, Velázquez y su siglo, fue publicada en La España Moderna entre 1906 y 1908 bajo la traducción de Eduardo Ovejero. Destacamos la últimas ediciones en español que incluyen estudios introductorios de gran provecho, cfr. Velázquez y su siglo, con prólogo de Karin Hellwig y traducción de Jesús Espino Nuño (Madrid: Itsmo, 1999) y Velázquez y su siglo, con prólogo de José Álvarez Lopera y traducción de Pedro Marrades (Madrid, 1999).

${ }^{15}$ Antonio Bonet Correa, "La originalidad e identidad del arte español según Carl Justi", en Carl Justi y el arte..., 14-15. torno al Retrato de Cristóbal Suárez de Ribera, habría que señalar que Mayer y Gestoso se habían conocido personalmente en 1906 y desde entonces mantuvieron una continua amistad epistolar ${ }^{16}$. El alemán había estado en Sevilla en varias ocasiones y juntos habían compartido largas charlas acerca del arte sevillano ${ }^{17}$. Por esta razón Gestoso consideró oportuno comunicar el descubrimiento del indicado retrato a Mayer, especialmente dado el curioso monograma que la pintura luce como firma de su artífice. A Mayer esas iniciales no podían sugerirle otro nombre más que el de Diego Velázquez, aún sin haber visto la pintura, pero se resistía a creer que el retrato fuera obra suya: "[no creo que] el monogramista D-O V-Z pueda ser Diego Velázquez porque no creo que ha firmado [sic] con un monograma sino las pocas veces cuando lo ha hecho, con su nombre y apellido. ¿No es posible que el retrato pueda ser obra de un artista que no es natural de Sevilla?" ${ }^{18}$. Un mes después, Mayer volvió a escribir, comunicándole a su colega que prefería no hablar sobre el cuadro pintado por el "monogramista" 19 " hasta que le enviara unas fotografías, postura que por otro lado parece la más sensata ${ }^{20}$.

José Gestoso anunció el hallazgo del polémico monograma a su también amigo

\footnotetext{
${ }^{16}$ Existe una nutrida correspondencia entre August L. Mayer y José Gestoso en el epistolario de este último, conservado en la Biblioteca Capitular y Colombina de Sevilla, véase: Carmen de Tena Ramírez, "El epistolario de José Gestoso (1852-1917) como fuente para el estudio de la historiografía artística española", Ars Longa. Cuadernos de Arte, oㅡ 27 (2018), 173-181.

${ }^{17}$ Sobre la presencia de August L. Mayer en Sevilla véase: Posada Kubissa, August L. Mayer..., 46-47.
}

${ }^{18}$ BCC, FG, Correspondencia 1910 vol. 1, no 111, carta de August L. Mayer a José Gestoso, fechada en Múnich el 28/04/1910.

${ }^{19}$ La virtud de la prudencia recomendó a Mayer a llamar al artífice del retrato "el pintor monogramista" o "el monogramista".

${ }^{20}$ BCC, FG, Correspondencia 1910, vol. 2, no 006, carta de August L. Mayer a José Gestoso, fechada en Múnich el 30/05/1910. 
el pintor y académico Narciso Sentenach ${ }^{21}$. Este le aconsejó que para probar una posible autoría de Velázquez del retrato era preciso fijarse, más que en el monograma, en las características formales de la pintura, que debía estudiar con precisión. Este detalle indica el interés de Sentenach por el nuevo método formalista; de la misma manera que Mayer, no se atrevió a sentenciar ninguna atribución sin antes contar con una fotografía para poder estudiarla él mismo ${ }^{22}$. Posteriormente le sugirió que escribiera un artículo al Boletín de la Sociedad de Excursiones ${ }^{23}$ para que expusiera el caso tal y como se había ido desarrollando, y de esta forma, pudiera presentar la pintura y su enigmática firma a los estudiosos del arte pictórico.

Fruto de la propuesta hecha por Sentenach resultó el artículo "Un monograma y varias interpretaciones" 24 , en el cual Gestoso lanzaba algunas hipótesis. Comenzaba esta publicación lanzando la posibilidad de que el monograma $\mathrm{D}^{\circ} \mathrm{VZ}$ pudiera identificarse con el nombre de Diego Velázquez, y, a pesar de encontrar puntos de conexión entre dicho artífice y el retrato, especialmente en su factura, que a su parecer presenta similitudes con el estilo de Pacheco, descartaba finalmente que fuera obra del célebre pintor. $\mathrm{Su}$ razonamiento se basaba fundamentalmente en el estudio y análisis del monograma; para Gestoso la "D" coronada por una

${ }^{21}$ Sobre este pintor y estudioso del arte, véase: Gonzalo Pasamar Alzuria e Ignacio Peiró Martín, Diccionario Akal de Historiadores españoles contemporáneos (Madrid: Akal, 2002), 585-586.

${ }^{22}$ BCC, FG, Correspondencia, 1910, vol. 1, no 124, carta de Narciso Sentenach a José Gestoso, fechada en Madrid el 06/05/1910.

${ }^{23}$ El Boletín de la Sociedad Española de Excursiones fue una de las publicaciones más importantes de la joven disciplina de la Historia del Arte. Entre sus colaboradores, se encontraban el propio José Gestoso, Manuel Gómez-Moreno, Vicente Lampérez y José Ramón Mélida entre otros.

${ }^{24}$ José Gestoso y Pérez, “Un monograma y varias interpretaciones", Boletín de la Sociedad Española de Excursiones, vol. 18, 3 (1910), 129-134. "o", pudiera ser una abreviatura de Diego o de Domingo, y que las letras " $\mathrm{V}$ " $\mathrm{y}$ " $\mathrm{Z}$ " son las iniciales del primer y segundo apellido, puesto que "los monogramas se forman con las iniciales del nombre y del apellido o apellidos, no con las letras primera y última de éste ó de éstos ${ }^{25}$.

Con este débil argumento y aún teniendo en cuenta el análisis de la factura pictórica, Gestoso descartó que su autor fuera Diego Velázquez ${ }^{26}$; propuso, en base a su convicción de que los monogramas sólo pueden formarse con las iniciales del nombre y los apellidos, que el autor del retrato pudiera ser un artífice del que aún no se conocía obra. En relación con esta posibilidad y demostrando un excesivo apego por la metodología positivista, aludió a los pintores cuyos nombres había ido recopilando durante sus investigaciones documentales, especialmente, en el Archivo de Protocolos Notariales de Sevilla, e insistió en la idea de que hay artistas de los que no se conoce obra alguna, a pesar de que se encuentren identificados documentalmente. Siguiendo esta hipótesis, apuntó a que pudiera ser que el autor del retrato fuera Diego de Zamora o Diego de Vera, nombres ya recogidos por él. Y finalmente, terminaba el artículo aferrándose a la praxis documental que tanto renombre le ha otorgado la historiografía sevillana, concluyendo "que es muy posible que el monograma corresponda á otro artista de los muchos que permanecen todavía ocultos en los inexplorados legajos de nuestros archivo de protocolos ${ }^{27 "}$.

Tal y como se ha podido constatar gracias al testimonio de August L. Mayer, Gestoso estuvo centrado más que en el estudio de la obra de arte como artefacto cultural, en la investigación documental de archivo. En una carta escrita a Carl Justi, Mayer le expli-

\footnotetext{
${ }^{25}$ Gestoso y Pérez, “Un monograma...”, 133.

${ }^{26}$ Irónicamente, este monograma que tantos quebraderos de cabeza supusieron a Gestoso y a sus colegas, fue empleado como logotipo para la celebración del IV centenario del nacimiento de Velázquez.

${ }^{27}$ Gestoso y Pérez, “Un monograma...”, 134.
} 
caba que durante su estancia en Sevilla en la primavera de 1908 había estado ayudando a Gestoso a identificar la obra de numerosos pintores de los cuales sólo había noticias documentales recopiladas por el sevillano, pero de los que no se conocían obras hasta ese momento ${ }^{28}$. Es decir, que tal y como nos señala el testimonio de Mayer y la praxis empleada para el estudio del Retrato de Cristóbal Suárez de Ribera, Gestoso comenzaba sus investigaciones desde los datos documentales para después cotejarlos con las obras de arte conservadas, método de trabajo que distaba mucho del empleado por la escuela alemana de Historia del Arte y muy especialmente por los discípulos de Wölfflin, entre ellos, el propio Mayer.

Pero a pesar del interés demostrado por Gestoso y la publicación del correspondiente artículo en el Boletín de la Sociedad de Excursiones, el Retrato de Cristóbal Suárez de Ribera regresó al olvido en el que durante tantos años había permanecido. Hubo que esperar hasta 1913, cuando el historiador del arte alemán Valerian von Loga publicó un artículo en el cual señaló, con argumentación mucho más rigurosa y hábil que la de Gestoso, que el artífice de la pintura había sido el célebre Diego Velázquez ${ }^{29}$.

Cuando se hizo pública la atribución del retrato, Valerian Van Loga (1861-1918) no era ningún advenedizo; admirador y seguidor de Carl Justi ${ }^{30}$, tenía en su haber una larga trayectoria como director de los Museos de

\footnotetext{
${ }^{28}$ Posada Kubissa, August L. Mayer..., 44; la autora toma la información de una carta escrita por Mayer y dirigida a Justi, fechada en Sevilla el 19 de mayo de 1908, cfr. Posada Kubissa, August L. Mayer..., 443.
}

${ }^{29}$ Von Loga, "Zur zeit bestimmung...", 282. Posteriormente publicó un artículo similar en español, con algunas modificaciones, incluyendo la refutación a las alambicadas hipótesis de José Gestoso en Valerian Von Loga, “Estudios velazquistas: la cronología de algunas obras de Velázquez", Boletín de la Sociedad Española de Excursiones, XXII (1914), 241-254.

${ }^{30}$ Posada Kubissa, August L. Mayer..., 194. Agradecemos a Teresa Posada su ayuda en la búsqueda de información biográfica sobre Von Loga.
Berlín, y como consecuencia de su práctica museográfica se había especializado en las tareas de catalogación. Su habilidad para las mismas ya se había puesto de manifiesto a comienzos del siglo XX, cuando publicó la monografía y el catálogo razonado Francisco de Goya. (Berlín, 1903), el primero en incluir fotografías $^{31}$. Diego Velázquez tampoco era entonces un desconocido para él; su primer trabajo acerca del artista fue Velázquez: Des Meisters Gemälde (Stuttgart, 1905), seguido por la monografía elaborada en torno a Las Meninas: Las Meninas: ein Beitrag zur Ikonographie des Hauses Habsburg (Viena, 1909); en este mismo año tradujo al alemán el célebre estudio de Aureliano de Beruete ${ }^{32}$.

Volviendo a nuestro retrato, la hipótesis de Loga no sólo era admisible desde un punto de vista meramente sujeto al análisis formal, sino que además encajaba a la perfección con el origen material del retrato. Cristóbal Suárez de Ribera fue el padrino de bautismo de Juana, la hija de Francisco Pacheco y esposa de Velázquez. Era lógico pensar que Pacheco tuviera una estrecha amistad con el clérigo, relación lo suficientemente importante como para que se encargara de pintar este retrato póstumo su mejor aprendiz, Diego Velázquez.

La atribución de Loga se ha mantenido hasta la actualidad pero pasó un tiempo hasta que fue plenamente aceptada. Uno de

${ }^{31}$ Se trata de una revisión profunda del catálogo que ya había hecho el conde de la Viñaza. Loga vino a España en 1897 para estudiar con detenimiento los grabados y dibujos de Goya, cfr. Jorge Maier Allende, "Relaciones hispano-alemanas en la historia del arte y la arqueología" en Carl Justi y el arte..., 56.

${ }^{32}$ A pesar de su importancia capital para los estudios de Historia del Arte en España y por supuesto en Alemania, la figura de Loga aún no ha sido estudiada por lo que tan sólo podemos hacernos eco de la escasa información que sobre él se ha publicado en relación a sus trabajos acerca del arte hispánico; véase la nota 26 de la versión traducida al español por Franziska Boørner y Eloi de Tera de: Julius Schlosser, "Francisco Goya", Verlag von E.A. Seemann, Bibliothek der Kunstgeschichte, $\mathrm{n}^{\circ}$ 26 (1922) (traducción publicada en ACTA ARTIS. Estudis d'Art Modern, 1, (2013), 183-224). 
los contrarios en reconocer este acierto fue el propio August L. Mayer, que hasta su obra de 1936 no admitió el retrato como de mano de Velázquez, aunque con reparos ${ }^{33}$. No dudamos de la profesionalidad de este último, pero creemos que los recelos ante esta nueva atribución que tan cerca tuvo de hacerla suya, estaba la mala relación que tuvo con Loga. El origen de la enemistad entre ambos historiadores de arte se encontraba precisamente en el estudio de otro pintor español, José de Ribera; Loga había publicado una reseña muy dura sobre la primera monografía publicada por Mayer, correspondiente a su tesis Jusepe de Ribera (Lo Spagnoletto). (Leipzig, 1908) $)^{34}$. Desde entonces son varios los testimonios que recogen la falta de entendimiento entre sendos historiadores ${ }^{35}$.

Una vez hecha pública la autoría del retrato por Loga en 1913 el Gobierno de España comenzó a interesarse seriamente por la pintura, y especialmente, por su permanencia en territorio español ${ }^{36}$. Salvador Ber-

\footnotetext{
${ }^{33}$ En la anterior de 1924 tampoco la había considerado como tal.

${ }^{34}$ Valerian Von Loga, recensión de "August L. Mayer, Jusepe de Ribera (Lo Spagnoletto)", Monatshefte für Kunstwissenschaft, no 1-6 (1908), 336.
}

${ }^{35}$ Mayer le pidió a Carl Justi que le indicara con plena libertad los errores que pudiera percibir en su monografía sobre José de Ribera, pues "sólo me duelen las críticas envidiosas y miserables como la del Sr. Von Loga", cf. carta de August Mayer a Carl Justi, fechada en Sevilla el 19 de mayo de 1908 y recogida por: Posada Kubissa, August L. Mayer..., 443; un año después volvió a aludir a la falta de compañerismo entre los historiadores del arte alemanes, poniendo como ejemplo su mala experiencia con Loga y la enemistad entre el propio Carl Justi y el crítico de arte Julius Meier-Graefe, Posada Kubissa, August L. Mayer..., 447.

${ }^{36} \mathrm{Al}$ margen de la merma patrimonial que produjeron en España la invasión francesa y el proceso desamortizador, no debe olvidarse que entre finales del siglo XIX y principios del XX salieron de España numerosas obras de arte codiciadas por coleccionistas y museos europeos y norteamericanos. La bibliografía actual sobre el tema es amplia: Immaculada Socias Batet, La correspondencia entre Isidre Bonsoms Sicart y Archer Milton Huntington: el coleccionismo de libros antiguos y objetos de arte (Barcelona: Universitat de Barcelona, 2010); María Do- múdez de Castro, marqués de Lema y durante aquellos años ministro de Estado, se puso en contacto con Gestoso para que éste interviniera y estableciera comunicación con la hermandad de San Hermenegildo, con el objetivo de adquirir la pintura ${ }^{37}$. Así, Gestoso se reunió con representantes de la citada corporación en nombre del marqués de Lema ${ }^{38}$, para preguntar si se prestaría la

lores Antigüedad del Castillo Olivares y Amaya Alzaga Ruiz, coord., Colecciones, expolio, museos y mercado artístico en España en los siglos XVIII y XIX (Madrid: Centro de Estudios Ramón Areces, 2011); Fernando Pérez Mulet e Immaculada Socias Batet, eds., La dispersión de objetos de arte fuera de España en los siglos XIX y XX (Barcelona: Universitat de Barcelona, 2011); José Miguel Merino de Cáceres y María José Martínez Ruiz, La destrucción del patrimonio artístico español. W.R. Hearst: "El gran acaparador" (Madrid: Cátedra, 2012); Immaculada Socias Batet y Dimitra Gkozgkou, eds., Agentes, marchantes y traficantes de objetos de arte (1850-1950) (Gijón: Trea, 2012); Immaculada Socias Batet y Dimitra Gkozgkou, eds., Nuevas contribuciones en torno al mundo del coleccionismo de arte hispánico en los siglos XIX y XX (Gijón: Trea, 2013); Immaculada Socias Batet y Dimitra Gkozgkou, eds., El arte hispánico en las exposiciones internacionales, circulación, valores y representatividad (Milano: Hugony ed., 2014); Esther Alsina Galofré y Clara Beltrán Catalán, eds., El reverso de la historia del arte. Exposiciones, comercio y coleccionismo (Gijón: Trea, 2015); Rebeca Recio Martín, ed., Museos y antigüedades. El coleccionismo europeo a finales del siglo XIX (Madrid: Ministerio de Educación, Cultura y Deporte, 2015).

Este fenómeno ha sido ampliamente estudiado por: Immaculada Socias Batet, "El reverso de la Historia del Arte: marchantes y agentes en España durante la primera mitad del siglo XX", en La dispersión..., 285-303, y más ampliamente en Agentes, marchantes...

${ }^{37}$ En efecto, el marqués de Lema mantuvo contacto epistolar con Gestoso respecto a este asunto, indicando en una de sus cartas que aguardaba las noticias que Gestoso le había anunciado respecto al retrato, cf. BCC, FG, Correspondencia 1914, nº 159, carta del marqués de Lema dirigida a José Gestoso, fechada el 16/05/1914.

${ }^{38}$ BCC, FG, Correspondencia 1914, no 144 , carta de Ricardo C. Caamaño dirigida a José Gestoso, fechada en Sevilla el 03/05/1905, en la que Gestoso anota: "Sobre el retrato del P. Cristóbal Suárez de Ribera que me encargó el Marqués de Lema tratase de ver si podía ser adquirido para el Museo de Madrid o para el de Sevilla. El Sr. Caamaño es el hermano mayor de la hermandad de S. Hermenegildo". 
hermandad de San Hermenegildo a ceder el Retrato de Cristóbal Suárez de Ribera, con destino a alguno de "nuestros Museos", y si así fuera, con qué condiciones ${ }^{39}$. La hermandad se negó en un principio a cualquier tipo de cesión, por lo que el marqués de Lema se vio obligado a intervenir personalmente en este asunto, y habló con el ministro de Instrucción Pública acerca del retrato pintado por Velázquez $^{40}$. Este a su vez, sugirió al arzobispo de Sevilla que se valiera de su influencia para que el retrato no saliera de España y que en todo caso, se ocupara de gestionar la cesión o venta del mismo al Estado a un precio razonable ${ }^{41}$.

Finalmente, los esfuerzos hechos por el Gobierno y por José Gestoso para adquirir el cuadro no lograron el resultado deseado, por lo que hubo que resignarse y confiar en que ningún anticuario iniciara las gestiones oportunas para tentar a la hermandad de San Hermenegildo a ponerlo en venta. Afortunadamente, la obra se conservó en el lugar para el que fue concebida hasta el 1 de abril de 1970, fecha en la que, mediante un convenio entre la hermandad de San Hermenegildo y el Museo de Bellas Artes de Sevilla,

${ }^{39}$ BCC, FG, Correspondencia 1914, $\mathrm{n}^{\mathrm{o}}$ 171v, borrador de carta escrita por José Gestoso, dirigida a Miguel García Miranda, fechada el 07/06/1914.

${ }^{40}$ El marqués de Lema, Salvador Bermúdez de Castro, dedicaba algunos ratos de ocio al estudio de Velázquez, vid. Salvador Bermúdez de Castro, "Un cuadro de Velázquez: El estudio del retrato del cardenal-infante Don Fernando", Revista de Archivos, Bibliotecas y Museos, t. 24 (1911), 248-266; Salvador Bermúdez de Castro, "Hallazgo de una obra de Velázquez", Museum, t. I (1911), 119-120.

${ }^{41}$ Esta gestión efectuada por el marqués de Lema fue relatada por su protagonista a Gestoso en una carta que le dirige, fechada el 02/07/1914, cf. BCC, FG, Correspondencia 1914, № 192. En este documento Gestoso anotó lo siguiente: "Refiérese esta carta a las gestiones que me encargó el Marqués de Lema para ver si conseguía de la Hermandad que vendiese al Estado el retrato del P. Cristóbal Suárez de Ribera, la cual se ha negado a hacerlo. Véase mi borrador del 7 de Junio". Este testimonio nos garantiza, por tanto, que efectivamente tanto José Gestoso como el marqués de Lema estuvieron directamente implicados en este asunto. fue depositada permanentemente en esta institución, facilitando al público la contemplación de una de las escasas obras de Velázquez que se conservan en la ciudad natal del célebre pintor ${ }^{42}$.

Este breve episodio nos ilustra acerca de la notable repercusión del método positivista en los estudios histórico-artísticos en España durante las primeras décadas del siglo $X X^{43}$. Esta circunstancia estuvo motivada por la formación recibida por los artífices de estas investigaciones de la generación anterior, que en su mayoría habían estudiado en la Escuela Superior de Diplomática de Madrid para poder ingresar en el cuerpo de Archiveros, Bibliotecarios y Anticuarios ${ }^{44}$. Su práctica historiográfica estuvo fundamentada en las llamadas ciencias auxiliares de la Historia, especialmente en el empleo de la documentación de $\operatorname{archivo~}^{45}$. También den-

\footnotetext{
${ }^{42}$ Rocío Izquierdo y Valme Muñoz, Inventario de pinturas (Sevilla: Junta de Andalucía 1990), 133.

${ }^{43}$ Método que según Gonzalo Borrás ha marcado la práctica historiográfico-artística en España, cfr. Gonzalo Borrás Gualis, "A modo de introducción: 100 años de Historia del Arte en España", en Gonzalo Borrás Gualis y Ana Reyes Pacios Lozano, Diccionario de historiadores españoles del arte (Madrid: Cátedra, 20069, 13.
}

${ }^{44}$ También algunos profesores de la Escuela destacaron por sus contribuciones al estudio de la Historia del Arte, como Juan Facundo Riaño, cfr. Leoncio LópezOcón Cabrera, "El papel de Juan Facundo Riaño como introductor del proyecto cultural del Catálogo Monumental de España", en El catálogo monumental de España (1900-1961): investigación, restauración y difusión, coord. por Amelia López-Yarto Elizalde (Madrid: Ministerio de Educación, Cultura y Deporte, 2012), 49-74; otro estudio sobre el personaje en Ignacio A. Muñoz González, "Arqueología y política en España en la segunda mitad del siglo XIX: Juan Facundo Riaño y Montero" (tesis doctoral, Universidad Autónoma de Madrid, 2016).

${ }^{45}$ Muchos de ellos también fueron miembros de la Real Academia de la Historia o de la de Bellas Artes de San Fernando. Sobre el panorama historiográfico de finales del siglo XIX y principios del XX en España, véase: Gonzalo Pasamar Alzuria e Ignacio Peiró Martín, La Escuela Superior de Diplomática. Los archiveros en la historiografía española contemporánea (Madrid: ANABAD, 1996); Ignacio Peiró Martín, Los guardianes de la Historia. La historiografía académica de la Restauración (Zaragoza: 
tro de este grupo se encontraban profesores de las Escuelas de Bellas Artes, como el propio José Gestoso, tratándose en definitivita de autores de encomiable labor pero que por motivos generacionales no lograron alcanzar la profesionalización a la que llegaron otros como Manuel Gómez-Moreno Martínez o Elías Tormo ${ }^{46}$.

En el proceso de profesionalización de la Historia del Arte en España fue esencial la colaboración mutua entre investigadores españoles y extranjeros, tal y como hemos querido exponer a lo largo de este artículo. Como ya ha sido señalado por Jesusa Vega, se hace imposible recorrer la historia esta disciplina en nuestro país sin atender a estas aportaciones foráneas, no tanto por su contribución a proyectar internacionalmente el arte español como por el impacto de sus métodos de trabajo en la historiografía artística española ${ }^{47}$.

Esperamos que esta contribución sirva para ahondar en el conocimiento y en el análisis de la Historia del Arte en España desde sus comienzos. El estudio del pasado promueve la reflexión acerca de la deriva teórica y metodológica que ha tomado nuestra disciplina, y nos ayuda a comprender su situación actual y a proyectar nuevos retos para su avance, desarrollo y proyección en la sociedad contemporánea.

\section{BIBLIOGRAFÍA}

Ainaud de Lasarte, Joan M. "Pinturas de procedencia sevillana". Archivo Español de Arte, no 73 (1946), 54-63.

Alsina Galofré, Esther y Clara Beltrán Catalán, eds. El reverso de la historia del arte. Exposiciones, comercio y coleccionismo. Gijón: Trea, 2015.

Institución Fernando el Católico, 2006).

${ }^{46}$ Borrás Gualis, "A modo de introducción...", 20.

${ }^{47}$ Jesusa Vega, “La Historia del Arte y su devenir en España", en La Historia del Arte en España. Devenir, discursos y propuestas, coord. por Álvaro Molina Martín (Madrid: Polifemo, 2016), 86-87.
Antigüedad del Castillo Olivares, María Dolores y Amaya Alzaga Ruiz, coord. Colecciones, expolio, museos y mercado artístico en España en los siglos XVIII y XIX. Madrid: Centro de Estudios Ramón Areces, 2011.

Bassegoda i Hugas, Bonaventura. "Pacheco y Velázquez". En Velázquez y Sevilla. Estudios, Sevilla: Junta de Andalucía, 1999.

Bermúdez de Castro, Salvador. "Hallazgo de una obra de Velázquez". Museum, t. I (1911), 119-120.

Bermúdez de Castro, Salvador. "Un cuadro de Velázquez: El estudio del retrato del cardenal-infante Don Fernando". Revista de Archivos, Bibliotecas y Museos, t. 24 (1911), 248-266.

Beruete, Aureliano de. Velázquez. Paris: Henri Laurens, 1898.

Bonet Correa, Antonio. "La originalidad e identidad del arte español según Carl Justi". En Carl Justi y el arte español, dirigido por Antonio Bonet Correa, Henrik Karge y Jorge Maier Allende, 13-23. Madrid: Centro de Estudios Europa Hispánica, 2015.

Borrás Gualis, Gonzalo y Ana Reyes Pacios Lozano. Diccionario de historiadores españoles del arte. Madrid: Cátedra, 2006.

Brown, Jonathan. Velázquez, painter and courtier. Yale: Yale University Press, 1986.

Mata Carriazo, Juan de. "Correspondencia de don Antonio Ponz con el conde del Águila". Archivo Español de Arte y Arqueología, no 14 (1929), 157-183.

Casquete de Prado Sagrera, Nuria. José Gestoso y Sevilla: biografía de una pasión. Sevilla: Ayuntamiento de Sevilla, 2016.

Cruzada Villaamil, Gregorio. Anales de la vida y de las obras de Diego de Silva y Velázquez. Madrid: Miguel Guijarro, 1885.

Gállego, Julián. Velázquez en Sevilla. Sevilla: Arte Hispalense Diputación Provincial de Sevilla, 1974.

Gestoso y Pérez, José. “Un monograma y 
varias interpretaciones". Boletín de la Sociedad Española de Excursiones, vol. 18, 3 (1910), 129-134.

Gestoso y Pérez, José. Biografía del pintor sevillano Juan de Valdés Leal. Sevilla: Juan P. Gironés, 1916.

Gestoso y Pérez, José. Catálogo de la Exposición de retratos antiguos celebrada en Sevilla en abril de MCMX. Madrid: Oficina tipográfica de Blanco y Negro, 1910..

Gestoso y Pérez, José. Sevilla Monumental y Artística. Sevilla: Oficina tipográfica de El Conservador, 1892.

Hellwig, Karin. "Carl Justi y los comienzos de la investigación sobre el arte español en Alemania". En Historiografía del arte español en los siglos XIX y XX, 309-322. Madrid: C.S.I.C., 1995.

Izquierdo, Rocío y Valme Muñoz. Inventario de pinturas. Sevilla: Junta de Andalucía 1990.

López Rey, José. Velázquez. Köln: Taschen, 1996.

López-Ocón Cabrera, Leoncio. “El papel de Juan Facundo Riaño como introductor del proyecto cultural del Catálogo Monumental de España". En El catálogo monumental de España (1900-1961): investigación, restauración y difusión, coordinado por Amelia López-Yarto Elizalde, 49-74. Madrid: Ministerio de Educación, Cultura y Deporte, 2012.

Maier Allende, Jorge. "Relaciones hispano-alemanas en la historia del arte y la arqueología". En Carl Justi y el arte español, dirigido por Antonio Bonet Correa, Henrik Karge y Jorge Maier Allende, 3968. Madrid: Centro de Estudios Europa Hispánica, 2015

Merino de Cáceres, José Miguel y María José Martínez Ruiz. La destrucción del patrimonio artístico español. W.R. Hearst: "El gran acaparador". Madrid: Cátedra, 2012.

Morel D Arleux, Antonia. “Un posible dibujo preparatorio del retrato de D. Cristóbal
Suárez de Ribera de Velázquez", Goya, nº 298 (2004), 32-36.

Muñoz González, Ignacio A. "Arqueología y política en España en la segunda mitad del siglo XIX: Juan Facundo Riaño y Montero". Tesis doctoral, Universidad Autónoma de Madrid, 2016.

Pantorba, Bernardino de. La vida y la obra de Velázquez. Madrid: Compañía Bibliográfica Española, 1955.

Pantorba, Bernardino de. Varia Velazqueña. Madrid: Ministerio de Educación Nacional, 1960.

Pasamar Alzuria, Gonzalo e Ignacio Peiró Martín. La Escuela Superior de Diplomática. Los archiveros en la historiografía española contemporánea. Madrid: ANABAD, 1996.

Pasamar Alzuria, Gonzalo e Ignacio Peiró Martín. Diccionario Akal de Historiadores españoles contemporáneos. Madrid: Akal, 2002.

Peiró Martín, Ignacio. Los guardianes de la Historia. La historiografía académica de la Restauración. Zaragoza: Institución Fernando el Católico, 2006.

Pérez Mulet, Fernando e Immaculada Socias Batet, eds. La dispersión de objetos de arte fuera de España en los siglos XIX y XX. Barcelona: Universitat de Barcelona, 2011.

Pleguezuelo Hernández, Alfonso. "Presentación", en José Gestoso y Pérez, Historia de los barros vidriados sevillanos: desde sus orígenes hasta nuestros días. Sevilla: Ayuntamiento de Sevilla, 1995.

Portús, Javier. “Justi y Beruete, con Velázquez de por medio". En Carl Justi y el arte español, dir. por Antonio Bonet Correa, Henrik Karge y Jorge Maier Allende, 139153. Madrid: Centro de Estudios Europa Hispánica, 2015.

Posada Kubissa, Teresa. August L. Mayer y la pintura española: Ribera, Goya, El Greco y Velázquez. Madrid: Centro de Estudios Europa Hispánica, 2010.

Recio Martín, Rebeca, ed. Museos y antigüe- 
dades. El coleccionismo europeo a finales del siglo XIX. Madrid: Ministerio de Educación, Cultura y Deporte, 2015.

Schlosser, Julius. "Francisco Goya", Verlag von E.A. Seemann, Bibliothek der Kunstgeschichte, $\mathrm{n}^{\circ} 26$ (1922) (traducción publicada en ACTA ARTIS. Estudis d'Art Modern, 1, (2013), 183-224).

Socias Batet, Immaculada y Dimitra Gkozgkou, eds. Agentes, marchantes y traficantes de objetos de arte (1850-1950). Gijón: Trea, 2012.

Socias Batet, Immaculada y Dimitra GkozgkoU, eds. El arte hispánico en las exposiciones internacionales, circulación, valores y representatividad. Milano: Hugony ed., 2014.

Socias Batet, Immaculada y Dimitra Gkozgkou, eds. Nuevas contribuciones en torno al mundo del coleccionismo de arte hispánico en los siglos XIX y XX. Gijón: Trea, 2013.

Socias Batet, Immaculada. La correspondencia entre Isidre Bonsoms Sicart y Archer Milton Huntington: el coleccionismo de libros anti- guos y objetos de arte. Barcelona: Universitat de Barcelona, 2010.

Tena Ramírez, Carmen de. “El epistolario de José Gestoso (1852-1917) como fuente para el estudio de la historiografía artística española". Ars Longa. Cuadernos de Arte, nำ 27 (2018), 173-181.

Vega, Jesusa. "La Historia del Arte y su devenir en España". En La Historia del Arte en España. Devenir, discursos y propuestas, coordinado por Álvaro Molina Martín, 21-173. Madrid: Polifemo, 2016.

Von Loga, Valerian. “August L. Mayer, Jusepe de Ribera (Lo Spagnoletto)". Monatshefte für Kunstwissenschaft, $\mathrm{n}^{\mathrm{o}}$ 1-6 (1908), 336.

Von Loga, Valerian. "Estudios velazquistas: la cronología de algunas obras de Velázquez". Boletín de la Sociedad Española de Excursiones, XXII (1914), 241-254.

Von Loga, Valerian, "Zur zeit bestimmung einiger werke des Velázquez", Jahrbuch der Königlich Preussischen Kunstsammlungen, vol. 34 (1913), 281-291. 